\title{
Peculiarities of childrencare and psycho-pedagogical rehabilitation of children born from HIV-positive parents
}

\author{
Tatyana Frolova ${ }^{1}$, Igor Titarenko ${ }^{2}$, Lyudmila Zakharova ${ }^{3}$ \\ Regional Specialized Children's Home "Zelenyy Hay" \\ Kharkiv, Ukraine ${ }^{1,2,3}$ \\ E-mail address: tatyanafrolova@gmail.com¹, titarenko1958c@gmail.com², \\ zakharova0806@gmail.com ${ }^{3}$
}

Keywords: children born from HIV-positive parents; psycho-pedagogical rehabilitation; social adaptation; disclosure of HIV-positive status.

\begin{abstract}
This article analyzes the experience in psychological and educational rehabilitation of children born from HIV-positive parents in the age from 2 months to 7 years. Working with children in this category is held in the Regional Specialized Children's Home "Zelenyy Hay", Ukraine, Kharkov.

The article describes the features of the rehabilitation and education of such children. In the literature, this problem is almost not covered. Therefore, the work was carried out individually with each child and the methods of pedagogical activity and social adaptation of children have been improved. It has been revealed that the children who had the coefficient of intellectual development close to normal children had undue fatiguability associated with a primary diagnosis. Taking into account this feature of children born from HIV-positive parents, changes were made in the structure of employment, the schedule of the day and individual approaches to each child.
\end{abstract}

\section{INTRODUCTION}

The specificity of the Regional Specialized Children's Home "Zelenyy Hay" is to work with children in orphanages (orphans, children deprived of parental care, including children whose parents, for health reasons are unable care for them.

Our students are children with central nervous system varying degrees. And from 2004 in the Regional Specialized Children's Home "Zelenyy Hay" are all children of Kharkiv and Kharkiv region born to HIV-positive parents aged from 2 months to 7 years.

This article analyzes the experience of psychological and educational rehabilitation of this category of children. Observations and analysis were conducted for ten years. Work carried out on the basis employees of the Regional Specialized Children's Home "Zelenyy Hay".

\section{PSYCHO-PEDAGOGICAL REHABILITATION OF CHILDREN BORN TO HIV- POSITIVE MOTHERS, THE REGIONAL SPECIALIZED CHILDREN'S HOME "ZELENYY HAY"}

When we started work on this direction, no experience of social adaptation and rehabilitation, education of kids we had. So at the beginning of the work they have been applied methodology and applications that previously used (program of education and training of mentally retarded preschool children (scientific author V.Turchinska) program upbringing and education of preschool children "Baby", "I am in world", "Ukrainian Environment" (authors O. Bilan, O. Didukh). Only in the course of this category of children revealed that the proposed programs and methodologies require significant changes and improvements. If the medical literature house the child was fully provided, while the literature on educational work and social adaptation of children born to HIV-positive mothers were not - had to build the work based on personal experience, intuition, observation of developments. 
First thing we encountered - a problem common development of children. During the initial examination, almost all children have the intellectual development factor close to normal. But social and educational neglect was more evident:

- unsociable children were poorly understood language addressed, did not respond to emotions and facial expressions,

- very fear of unfamiliar adults, there was no interest in others;

- children were immature skills of interaction with peers.

All these indicators point to the fact that children were still in deep isolation and dire lack of communication related to the underlying disease.

This was our first priority, for the decision which had to work with each child separately.

Later, while working with these children, was spotted by another feature of their behavior very fatigue. During the day and in the classroom staff began to notice changes in the behavior of children - even during a slight load points regime, the children began to refuse assignments, watching favorite shows, reading, shared games. There were attempts to link these denial that children are not able to communicate, insufficient supply of knowledge and skills. But after a long observation we have concluded that the main cause of this fatigue is the nervous system of the child related to the primary diagnosis and, probably because of its toxic effect on ARV therapy. It was separated distinguishing feature of children born to HIV-positive parents in IQ close to normal increased fatigue and informational to emotional stress. It is this pattern if fails to pay attention to it, can lead to deterioration of the health of the child, violation of cognitive processes, even to the depressed state of the child.

We solved this problem in several stages:

- For groups where children are brought up, was introduced flexible working regime of the day;

- was increased hours for recreation and kids games;

- personnel of these groups alone can change and alter activity of children, depending on the health status of the child (an individual approach to each child);

- elements sessions with children, regardless of the season, were transferred to the fresh air, and a group of children was divided into subgroups of 3-4 children;

- structure was changed classes:

Average class children divided into three parts:

- familiarization with new material,

- the ratio of new material with others,

- fastening material.

Given the peculiarity of children born to HIV-positive parents (increased fatigue), the structure of studies have been made following changes:

- the duration and sequence of the structural parts of classes varies, depending on the pet's health at the time of the occupation;

- acquisition groups for study conducted taking into account fatigue, and individual traits of each child, these same factors were taken into account during the selection of educational material.

\section{FEATURES DISCLOSURE OF HIV STATUS OF THE CHILD}

One of the key elements for proper physical and mental development of children is timely disclosure of HIV status to the child.

Based on the experience of the institution and age range of children who are in education and rehabilitation in our house child with this diagnosis, we have concluded that the disclosure of the status of children under six years is important, but has its own characteristics: feasibility disclosure of the status of children of 4 -s to 6 years is the need of medication, drop tests (more often than other children), more frequent visits to doctors, the importance of compliance with hygiene procedures.

However, the baby should be psychologically prepared to accept specific information about their illness. One indicator of such willingness is that the child begins to ask questions about its 
adult disease, namely on the need for healing, especially the regime, and other tests to which the child must get honest answers. At this point, should take into account the age of each child feature to receive the information, the ability to analyze and make appropriate conclusions. Therefore, the information about the child's illness, we give dosed in the form of tales - "Travelling droplets Princess", "The Tale of the evil virus and a little girl." In these tales we know kids in an accessible form of HIV, its effects on the human body and means of suppression virus. That is what should and can do a kid for his full development.

It is important to convey to the child that the AIDS virus does not disappear completely, but he can fight and live a full life. The key to this is systematic and timely medication intake, keeping hygiene, caution in relationships with peers, avoiding injuries, caring for their health.

This information is presented in stages in class on the basics of health, during the staging of fairy tales, theatrical performances involving children themselves, reading relevant literature for children.

It is noteworthy feature of the psyche of the child of preschool age, which helps in disclosing HIV status: young children perceive more optimistic about their health problems, their mind is plastic, the baby has little experience in the accumulation of negative emotions that quickly cropped positive aspects in his life.

Therefore, we believe that disclosure of HIV status of a child under the age of six years, dosage of and availability of information in a heap of psychological perception-age child becomes the basis of correct perception of the disease, the importance of taking antiretroviral therapy and care of their health.

\section{INTEGRATION OF HIV-INFECTED CHILDREN IN THE LEARNING ENVIRONMENT}

HIV-infected child, perhaps even to a greater extent than other children need active life filled with socializing with others and love of family. There is no reason to isolate HIV-positive child in the family. HIV infection in a child is not an obstacle to visit her children's institutions with uninfected children. Personal contacts with HIV-infected child are safe, especially if a safe level of viral load.

HIV-positive children have the same right to signup to school and access to education. They may be in preschool and secondary schools of different types:

- together with other children, if the number of HIV-infected children or children born to HIV-infected mothers (to clarify the diagnosis), at least six people in the group;

- in separate groups if the number of children over six.

It is advisable that child to school for a certain time visited the children's group, has acquired social skills with peers and adults [1]. We need to teach it without danger to themselves live, communicate, play with other people.

Teachers have to understand that HIV-infected child in the learning environment does not pose a threat to the health of other children, but she may need more emotional and educational support. When dealing with HIV-positive children, through saliva and tears, sweat excretion, insect bites, through air, water or food, using common utensils, towels, infection transmission. In addition, the virus can not withstand the impact of air and survives outside the body for several minutes.

But other people can pose a threat to HIV-positive child. A disruption of the immune system's own children living with HIV are more susceptible to various infectious diseases. Because of this fact, students or employees of the institution with signs of infectious disease may pose a real danger to the child who is living with HIV. During the high incidence of various infections (eg seasonal respiratory or intestinal diseases) students living with HIV, if their HIV status is known, should be advised to refrain from attending classes [2, p.19].

Asymptomatic course of illness allows children with HIV study in school because their educational opportunities should not differ from other children. Children and adolescents with HIV should not be excluded from school or isolated in a school environment. Confidentiality of HIV infection must be preserved for disclosure of HIV status requires the consent of the parents. 
The leaders, medical workers and other educational institutions, which due to certain circumstances become known HIV-positive student or his immediate family are obliged not to disclose this information, which is confidential personal information to third parties - other staff, pupils, their parents etc. Otherwise they may incur disciplinary, administrative or criminal penalties under applicable law.

Required tolerant attitude to HIV-positive children, and for this to happen change in consciousness. To these children received free access to school and there have not experienced oppression from other children, school personnel and parents of classmates, you need to destroy in the minds of men that the established linear causation and convincingly demonstrate that HIVinfected children do not constitute a danger to classmates. Evidence of this and should give the public and justify the protection of HIV-infected children hotel and preschool education.

The spread of HIV in the school has never been documented; known cases where a child with HIV, learning in a team, become a source of infection to other children. Therefore, fears and prejudices in relation to it must be eliminated by appropriate education of all school staff [3, p. 72].

Children born to HIV-infected mothers have some problems with socialization in the school environment. Unlike other HIV infection is accompanied by stigma (stigma - stamp) and the negative attitudes of society, which creates additional problems. Training at the school gives a sense of normal life for children and adolescents with HIV infection and offering opportunities for socialization that are important to their full development. Going to school reduces feelings of alienation, loneliness and reduces feelings of isolation and rejection, and solves the problem of contacts. People with HIV have a right to participate in all events at the school to reflect their health.

\section{THE ROLE OF THE TEACHER IN THE EDUCATIONAL INTEGRATION OF CHILDREN BORN TO HIV-INFECTED MOTHERS}

The teacher in the first place, is to conduct a preliminary advisory and educational work, directed the adoption of the ideology of inclusive education, parents of healthy children and teaching staff:

1. Participation in parent meetings, trainings, seminars, stands design, distribution sites, publications in mass media and the Internet; parents need to give an answer to the question "What is inclusive education", its basic principles, what are the characteristics of HIV-infected children, the benefits of inclusion of children with special needs, possible difficulties and problems.

2. An anonymous survey of parents and monitoring the results on which to draw conclusions for future work. You can also use these techniques: Diagnosis overall communicative tolerance (VV Boyko) Diagnostic capacity for empathy (A. Mehrabian, N. Epstein); making other diagnostics (on a scale Feyya).

3. Individual interviews with parents who do not want to teach their children with HIVinfected children:

- determine the causes reluctance;

- finding ways to address these causes.

4. Compatible with the management of the school to meet students, parents and school staff with competent medical specialists to work with people living with HIV.

5. With the support of the charitable organization "People living with HIV" with the children and their parents to visit the orphanage, which brought up the children born to HIV-infected mothers, and the Center for AIDS to:

- review of daily life of workers and children;

- communication (direct contact) with adults, babies living with HIV.

6. Volunteer aid (students - volunteers, parents - students - volunteers) orphans born to HIVinfected mothers to form a tolerant attitude to children in this category.

7. With the support of the school management and parents of students who agreed to the introduction of the children's collective child with a disability, organize a separate class of inclusive education. 
The teacher plays an important role in the formation of HIV-positive children self-esteem and assist them in making children's groups. The teacher determines the atmosphere of class relations in class. When other students in the class see that the teacher accepts and loves student with HIV, they will also take the child.

Teachers can teach students to show compassion and sympathy towards others, to control negative emotions such as anger, sadness and anxiety, to show how their words and actions affect others. Given the age he spends playing games, playing situation, discuss how to overcome barriers to learn together.

The teacher as a role model and as a replacement parent, encourages partnerships between HIV-infected and the other children in school, life, communication and so on.

A student with HIV are often physically weaker than their peers because he is sick more often and longer, in addition to the usual disease difficult to treat. Therefore, the task before the teacher be careful not to reinforce his feeling that he is different from other students. Second, the teacher brings to the HIV-infected students about what is more similarities than differences between them and their peers. Third, the teacher brings HIV-infected children that their feelings, life, relationships are the same as with peers.

Students with HIV have the right to enjoy a full life as possible, and should not be denied the opportunity to receive the education to the maximum of their abilities. Buyers students born to HIV-infected mothers, according to their right to basic education should reasonably consider within the school environment. The main task of the teacher - to promote the positive and help students that are emotionally vulnerable, so they are not sharply refused to normal life.

The teacher should treat each class member with respect and to show that he or she appreciates each student, including a child with special needs. Teacher, thus, should listen and understand the problems of children's development strategy to offer their strengths.

The next thing is to do a teacher - is to work with a psychologist and medical workers in school. They will help determine the physical and mental development of the child, to provide moral support and to create an atmosphere of trust, which can successfully solve problems.

A successful teacher should:

- respect the dignity, beliefs and constitutional rights of students, in particular, the right to privacy and the privacy of children;

- confirm the uniqueness, individuality and specific needs of each student:

- manage and support the child in realizing their potential;

- Avoid all forms of humiliation, physical or emotional abuse of the child;

- use appropriate language and behavior in his interaction with students;

- to act so as to command respect from the students;

- take reasonable measures to ensure safety;

- encourage students to work together and not compete;

- help children to feel that emotions are completely normal part of life, there is nothing shameful or weak associated with the presence of emotions.

Regarding sex education, make sure that the children know about HIV / AIDS in a very correct manner.

For example, using pictures and play:

- teach children how to keep your body healthy and how to avoid anything that could hurt him;

- teach children to never talk to a stranger, especially not to get into her car;

- help thinking about the fear of change in relation to HIV-infected;

- convince children that people with HIV / AIDS are not bad, this illness is not a punishment for something.

Teachers who support the inclusion of students with special educational needs should be sensitive to their own attitudes and feelings, as well as the specific needs of students. They need to gain knowledge and understanding about the factors that cause bias and should be honest enough to recognize them in their behavior. Clarity about their own strengths, vulnerabilities and needs is a 
necessary step in preparing teachers for inclusion. Only when this is achieved, they can influence the attitude of the school community to students with disabilities [4].

\section{CONCLUSION}

Favorable learning environment to help children living with HIV successfully learn, preserve and strengthen the physical and psychological health, resist depression and negative feelings, cope with the difficulties associated with periods of illness, need constant medication, maintaining a secrets of his HIV status.

Despite the complexity of health, which is associated with the main diagnosis, these children are no different from other kids. They have their own identity, individual abilities and talents, and our responsibility is not only psychologically and information to prepare these children for future life in society, but also to help them discover and develop their personality all that in the future they felt necessary and confident.

\section{References}

[1] L.V. Zakharova, The organization of training of HIV-infected children in the secondary schools, in: K.A. Yurieva (Eds.), The methodology of modern scientific research: materials of scientificpractical conference of young scientists, Kharkiv, 2014, pp. 20-21.

[2] L.A. Glazyirina, A.I. Zagaynova, T.A. Epoyan, Training, support and protection of students and education workers living with HIV or affected by the HIV epidemic: Practical advice on implementation of the policy in relation to HIV in the education system in Eastern Europe and Central Asia, Moscow, 2011.

[3] N.V. Kotova, O.O. Starets, HIV-infected children: medical care, psychological support, social support, legal protection, Kyiv, 2010.

[4] L.V. Zakharova, The role of the teacher in the educational integration of children born to HIVinfected mothers, in: O.E. Josan (Eds.), Ideas human pedagogy and a modern system of inclusive education: collected materials off All-Ukrainian scientific conference dedicated to the 97th anniversary of V. Sukhomlinsky, Kirovohrad, 2015, pp. 146-150. 